\section{omignar comonteamosts.}

\section{FACTS AND OPINIONS RELATING TO TU. BERCULOSIS ; WITH COMMENTARIES.}

\section{BY HENRY ANCELL, Surgeon.}

ro. vr.

I HA.VE considerable difficulty in approaching the subject of the present communication, inasmuch as it is my misfortune to differ very widely in opinion, on some important points, with a gentleman who deservedly enjoys a high roputation as a physiologist and pathologist; and I feel called upon, in elf-defence, to criticise a portion of his writings.

In the second volume of Mr. Paget's Lectures on Surgical Pathology, delivered at the Royal College of Surgeons of Inngland, and published during the last year, the sixteenth lecture, embruces the subject of "Tubercle". In this locture, Mr. Paget enunciates the general doctrine of scrofinlons and traberenlons diseaces, as it is taught at the Collewe of Burgeone, and, I presume, in the sehool of which he is a distinguished professor. This doctrine differs so essentially in some of its fundamental principles from that which I have inculcated in my work On Tuberculosis, that I trust I shall be excused examining it in detail. If Mr. Paget's views ware admitted to be correct, I should have to modify my own to a considerable extent.

The general tendency of the lecture is to prove that, both in their nature and their causes, "scrofulous" and "s tuberculous" affections are different diseases. In the first place, Mr. Paget deals with the term "scrofula" thus: he states, that it is a vague term; that it includes come diseases that are, and many that are not, distinguished by the production of tubercular matter; that both tuberculous products and varieties of degenerate lymph and pus are especially frequent among persons of the "scrofulous" or "strumous" constitution; that degenerate lymph and pus are often described as "scrofulous matter"; that " scrofula and tuberculous disease are often regarded as the same disease, and that it is impossible to clear the confusion arising from the interchanging use of terms". Mr. Paget undertakes, nevertheless, to give the meaning of these terms, "according to general usage".

"Scrofula" or "struma", then, "is generally understood as a state of constitution distinguished in some measure by peculiarities of appearance even during health, but much more by peculiar liability to certain diseases." The ex:amples of these diseases given by the author are, pulmonary consumption, swellings of lymphatic glands, certain chronic inflammations of joints, slowly progressive "carious" ulcerations of bones, chronic and frequent ulcerations of the cornea, ophthalmia, chronic abscesses, purulent cutancous eruptions, habitual swelling and catarrh of the mucous membrane of the nose, habitual swellings of the upper lip.

After remarking, that it is difficult to say what all these diseases, and many more of a like kind, have in common, the following dictum is laid down:-Certainly they are not all tubercular diseases; and then we are informed that, of the latter, we may make a group, defined by the peculiar morbid product-tubercle.

It is thus rendered apparent, that Mr. Paget endeavours to sustain the distinction between scrofulous and tuberculous diseases by removing from the former all those preeminently scrofulous affections in which tubercle is manifested; making a distinct group thereof, under the designation of "tubercular diseases".

I am not prepared to deny that there exists a necessity for greater caution than has hitherto been exercised in distinguishing true from pseudo-scrofulous affections. If, on the one hand, it can be shown that all the more sovere scrofulous diseases are tuberculous in their origin, progress, and tendency, on the other, there can be no doubt that alight chronic affections, totally devoid of any tuberculous tendency, are sometimes, upon insufficient grounds, lanosinated necofula. The penctioil importance of a cor- rect dingnosis of all such sfections is obrious. Soience would gain nothing, howerer, by altering the meaning of the word scrofuls, and limiting it to such affections; nor is this Mr. Paget's object. On the contrary, it is clearly stated by this gentleman, that in the above list of diseasee, for the most part unquestionably "serofulous", some are tuberculous, and some are not; and that the two groupe differ from each other in their nature and causes. Wo are not informed which of the particular diseases it is that constitutes each group, except so far as the existence of tubercle is concerned. Where tubercle is not deposited, the disease belongs to the scrofulous group; and where tubercle occurs, it belongs to the tuberculous group. That the basis upon which Mr. Paget founds this distinetion may be clearly understood, I will give it in his $0 \mathrm{~mm}$ words :-

"As contrasted with other diseases of the same forms and parts, the scrofulous diseases are usually distinguished bJ mildnees and tenacity of symptoms; they arise from comparatively trivial local causes, and produce, in proportion to their duration, slight effects: they are frequent, but not active. The general state "on which they depend may be produced by defective food, with ill ventilation, dampness, darkness, and other depressing influences; and this general state of constitution, whether natural, or artificially generated, is fairly expressed by such terms as 'delicacy of constitution', 'general debility', 'defective vital power', 'irritability without strength'. Such terms, however, do not explain the state that they express; for they all assume that there are in human bodies different degrees of vital power, independent of difference of material, which is at least not proved."

To the principal points in this enunciation, with all due deference to the anthor, I must enter my protest.

In the first place, that the terms "delicacy of constitution", "general debility", " defective vital power", "irritability without strength", "assume that there are in human bodies different degrees of vital power, independent of difference of material", is itself, in my mind, an assumption. I had been taingt to believe that our opinions respecting vital power have a much more philosophical foundation, and that the idea in the latter part of the quotation had been long since repudiated, as striking at the root of physiological science, and subversire of what are accepted.as correct principles of pathology.

I presume that the word pover is employed by Mr. Paget advisedly, and that it will be conceded, in accordance with the received principles of philosophy, that the existence of vital power inherent in an animal, or in an organised structure, can only be known by some one or more of the manifestations of vital force.

I presume also there can be no doubt that vital power may be varied in degree in the same individual or part; but that, as in the case of other powers of nature, the degree of power can only be distinguished by the effects it produces. In a few words, the principle, "that every change we observe in the condition of bodies must be considered as an effect indicating the agency, characterising the kind, and measuring the degree of its cause," applies as much to vital power and its effects as tw any other of the powers with which matter is endowed.

It is in fact upon the general datum quoted in the last paragraph, that, in living bodies, the existence of vital power, in contradistinction to the other powers of nature, is universally admitted.

But Mr. Paget asserts that the terms in question assume different degrees of vital power, independent of difference of material, by which must be meant, if anything, indopendent of any change or modification of matter. How can Mr. Paget prove this, or know it? What means is there of measuring the degree of vital power in a living being or an organised structure, except by some of the manifeatations of vital force, and accordingly by some change or modification of living structure? The proposition appears to me to be an absurdity. We might as well afirm that the powers of nature may be separated from their subjects, 
whongh wo lnow that a power which inheres in nothing is imporible.

Tho terms in queation, then, sceording to my apprebencon, do not involve, in the medical reasenings of the prent day, any such an inconaintoney; and I must regand the acoumption as Mr. Paget's own, which, he admits, has neen proved, but which he adopts as the basis of his iows of the nature of scrofula. I dispute the validity of the assumption, and hold to the contrary thereof, that, as of the other powers of nature, our only means of jedging of the degree of vital power in an organised structure is by its effects, or the manifestations of vital force; that functional activity is as necessarily attended with structural change as that every effect must have - canse; that there is no such thing in man's corporeal existence even as thought without a change of matter in the material organ; and that the assumption that there are different degrees of vital power in human bodies, independent of difference of material, is inadmissible.* I must confess I do not see what Mr. Paget gains thereby; but if we were to admit the probability of the assumption, and, although not proved, that it is perfectly allowable to found an argument thereon, the conclusion would still remain to be proved. In such a mode of reasoning, it is usual to submit the conclusion to observation and experiment for the proof. To argue upon an improbable or a false assumption, and then to assume that the conclusion is true, would be about as great a deviation from true logic as could well be conceived.

The next important point in Mr. Paget's enunciation of his doctrine is, that "scrofuls", or " the general state of constitution upon which scrofulous diseases depend, whether generated naturally or artificially", is fairly expressed by the terms quoted. In other words, "delicacy of constitution", "debility", "defective vital power", "irritability without strength", are one and all "scrofula"; that is to say, constitutional scrofula; and scrofula is neither more nor less than these terms imply. The terms in question are sufficiently familiar to every reader, but it will assist us in the discussion of this subject, and prevent misapprehension, if, in the first place, we briefly consider each of them.

1. Delicacy of Constitution. This expression is doubtless often employed vaguely, and does not refer more to vital power than to obvious structural defects. I believe that writers in general attach to the idea a certain delicacy of fibre, of colour, and of general structure. Individuals, however, looking strong and healthy, are often said to have delicate constitutions, in which instance the expression refers more especially, perhaps, to a low degree of vital power concealed, as it were, under an apparently vigorous organisation. But, in the use of this expression, the peculiarities which mark the scrofulous constitution are not implied. We may say of an individual, "His constitution is delicate, but he is not scrofulous"; or, "There is delicacy of constitution, but no evidence of, and no reason to believe in the existence of, scrofula". In fine, the structural and functional peculiarities of the "delicate constitution", and those of the "scrofulous constitution", are different. The description of the latter involves to a great extent, and sometimes wholly, that of the former, but something more: the description of the former, per $\&$, does not comprise the peculiarities of the latter.

2. General Debility. This term is included in the former. It implies a diminution in degree of the manifestations of vital force. It forms unquestionably a most important feature in the scrofulous constitution; but, taken alone, it does not constitute scrofula, or represent, or "fairly expreas" scrofula, any more than it does scurvy or typhus Ever.

- Loet I chould be misunderatood as holding that mind itself is matter, I corafl repudiate such an idea. It is meant only io bo anrmed, is sceordance,

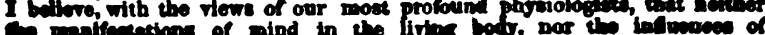

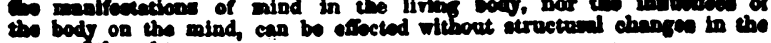
the bed on the

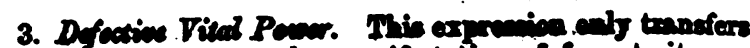
the explanation from the manifectation of forvo to its unknown cause. Admitting that the moet goneral charncter of scrofula in defoctive vital power, the difference, as compared with the state of health, can only be meacured by structural and functional peculiaritioe. If we were taken into the wards of St. Bartholomer's Hoepital to see a well marked case of "defective vital power", it would puzsle us to determine what we were about to witness. We should revolre in our minds typhus fever, gangrene, ulcerntion of the bowels, organic disence of the etomach, atrophy of the heart, and perhape, lastly, scrofula

4. Irritability without Strength. I presume this term is used in the general, and not in the Hallerian sense. It is another mode of stating the Hunterian doctrine of "an increased disposition to act, without the power to act with", or "over action to the strength of the parts". Nor, as respects irritability, I know rery well that there was a time when some pathologists viewed function abstractedly from the organ, and held that functional activity might be more or less independent of organisation; but irritability is only one of the manifestations of the vital force, or vital forces, and, as such, is amenable to the received doctrine of forces already quoted. Irritability exists both in particles and masses of matter, and is not exclusively limited to solids or fluids; for the blood corpuscle, and even the molecular base of cells in the animal fluids, as well as the cells constituting membranes or bones, alike partake of it ; we know of its existence only by the molecular or sensible motions of, or changes in, any organ, structure, or part. In its most extended sense, it is employed as a subetitute for the term vital power; and then it is regarded as essential to the molecular motions of every particle of organised tissue. The expression, "without strength", must either refer to the power to which those manifestations of vital force designated as irritation are referred, or to the subjects of that power, the organised structures. To the former alone it cannot refer, inasmuch as, if intended to imply a greater degree of irritability, the organic structure remaining the same, the simple expression, "excess of irritability", would be employed; and if to imply a diminution, it would be designated "defect or want of irritability". It must therefore refer to the subject, and accordingly to some modification of structure in consequence of which the irritability of a part, while, in point of fact, natural, or in excess or in deficiency, is readily excited, and readily exhansted, and perhaps readily renewed. That this is a characteristic of the scrofulous constitution, may very readily be admitted. In fact, it is a very general concomitant of debility, under particular circumstances, as when that debility is not carried too far; but it is no more scrofula than simple debility is scrofula. "Irritability without strength", or "debility with irritability", is a mode of the manifestation of vital force common to scrofula and numerous other diseases.

Every fact of pathology is against the assumption that the scrofulous constitution or predisposition is a state of simple debility or delicacy. Iet a healthy individual be subjected to any of the causes of simple "debility", and reduced to a state of the most extreme "delicacy", "defective vital power", or "irritability without strength", such as starvation, hæmorrhage, scute disense, or depletion, scrofula will not thereby be necessarily produced. There must exist something more to constitute the predisposition to serofulous affections, and to cause the tumid lip, the enlarged tonsil, the tondency to glandular disease, the affections of the bones and joints, ophthalmias, otorrhcoas, and other diseases having the special characteristics of scrofula. We 200 a woman, for instance, reduced by hromorrtinge to the moat extreme point of debility, paeaing through the most tedious convaleacence, and ultimately recovering without one sign of scrofula ever having precented itself. We sec an iminat, again, literally starred to death by the most gradual procens of inanition, with the ame abeence of the

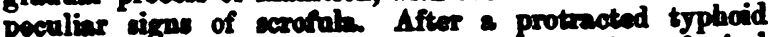

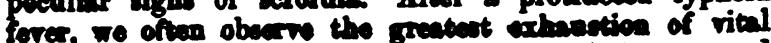

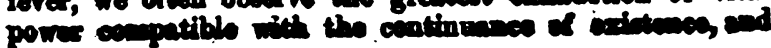




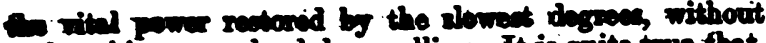
che thing as a gladular swelliog. It is quito true that, in all the casen, enofula mos be and roty frequenth is, Freoed; and that the eirenmeturnes attending woh are well celoulated to promote its developmont, especially where then in a pro-axinting dispocition. But scrofula is pot a nececcary or even a generenl result of such cases; and Drene it eccurs, the sum total of it signs and symptoms inticato a pathological condition ouperadded to, and combined with, the state of debility or defective vital power.

The fundameatal principles I have just edvoented and in wich Mr. Paget and myself appear to take very different views, do not limit themselves to the doctrine of tuberenlous dieneses, bat affect the whole theory of medicine, and, without appealing to a long array of physiologists to show that my viow is supported by high authorities, I will refer to two or three. Dr. Curpenter, who has fallowed the progress of physiological scienco perhaps more closely than any other individual, and has himself very matorially aided it in some of its highest branches, when giving an account of the novel bat highly important doctrine of a correlation of the physical and rital forces, refers vital phenomens to dynamical and material antecedents or causes, the one supplying the force or power, and the other the conditions of its manifestation, but he never falls into the error, so much stigmatised by Fletcher, of regarding the former as something substantivl which may be, per se, accumulated, diminished, or exhausted. Tiedemann, again, speaking of "irritability" or "ercitability", states distinctly, "we are not to imagine it as an isolated farce, merely attached to organisms, and objectively different from their organic constituent mattor, capable of change, of exaltation or diminution, without a simultaneous change in that matter. On the contrary, we are to regard it as a quality founded on the specific state of the organic matters and the organisation (organism), and altogether dependent on these." If we were to admit Mr. Paret's doctrine, that vital power may be increased or diminished in organic matters, independent of difference of drocture, where would be the limit of the increase? We shoold then be called upon to admit, with the enthusiastic Brown, that every individual may be endowed with a certain portion of vital power and irritability at birth, which lasts during the period of his existence, and that the germs of the first individasl contained the sum of the vital force of the whole of his race,-as remarked by Dr. Carpenter,- "a nectuatio ad absurdiem".

The preceding remarks relate to Mr. Paget's views of the nature of scrofula, and are founded upon the paragraph qnoted, in which he gives some of the primary characteristics of that disease. It is not my intention to enter into a description of those modifications of structure and function which constitute the scrofulous or tuberculous constitwion, which I have done minutely elsewhere. It was necessary, however, not only to state the author's opinion of the nature of scrofula, but to examine the grounds upon which it is founded before we could judge of the distinction which he draws between scrofulous and tuberculous ditcases. We have now to examine Mr. Paget's attempt to ectablish an essential difference between these. The proofs given are reducible to the three following heads :-

2. A state of "general debility" or "delicacy of constitutica" upon which scrofulows affections depend may be produced by defective food, with ill ventilation, dampness, dartuess and other depressing influences; whereas, the "tubercular diathesis" which precedes the formation of twbercle is not (the suthor says acarcely) producible by any exticenal agencies except climate.

II. Fearly all diserses may coexist with the scrofulons, but some aro nearly incompatible with the tuberculous affoctions.

III. Mrny inctances of scrofula exist with intense and long continued disease, but without the deporit of tuberale, and a man indences of traberculous discase without any of the nar-tubarenlous affections of carafula

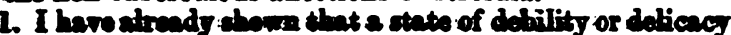

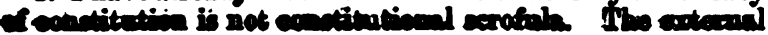

infinences enimented by Mr. Paget, vis., defective foch, with ill ventilation, dampness, dartnees, and other doprese ing infuences, will produce debility; but, when theee offects terminate here, then we have no serofula. Moreover, either of these infuences existing to a certain degree alone will produce debility, but it is extremely doubtful if any one, in sarg dogree, can alone produce scrofula (On Twberculosis, p. 45.0); certainly none in any degree or continued for any period, are followed necessarily or uniformly by that disease. At the same time, the combinstion of circumstances enumerated by Mr. Paget involve those under which scrofula as well as debility are known to arise. But what combiustion of these circumstances it is, how the effect is produced, and what the essential nature of the change, we do not at present know. This, in fsct, is the greatest pathological problem relating to this disease.

After defining scrofula as a state of debility, and having sought to establish that the causes referred to produoe scrofula, Mr. Paget, with some qualification, denies that they can produce the state of constitution which precedes the formation of tubercle. He affirms that tubercle is "scarcely producible by any external agencies except chimate". Thus scrofula and tuberculosis are declared to be different diseases not only in their essential nature, but as respects their causes. It would be important to know, if climate be the sole cause of tuberculosis, what climate it is? or what change of climate? After a very careful examination of every thing that reached me, the prevalence of tuberculosis in different climates, and the influence of climate over the production of this disease, I was led by facts to the conclusion that the disease may occur in any climate, that there is no regular or direct ratio between any kind of climate and its frequency, and that the habits and customs of mankind over-ride all climatic influences. (On Tuberculosis, pp. 508-37). I state unhesitatingly, that if the slightest dependence is to be placed on the recorded observations of the most experienced observers (idem, p. 545) the circumstances enumerated by Mr. Paget as the causes of that state of constitution upon which scrofula depends, are just those which are most efficient in producing, not only the development of the tuberculous "diathesis", but the actual deposit of tubercle. Subject a body of men to the prescribed circumstances, even in their own climate, in almost any part of the globe, and consumption will be produced. A chimpanzee, taken from his native woods, imprisoned in a damp, dark cellar on its borders, and kept on scanty diet, will die in a few weeks with tubercle in many of its vital organs. Bimilar conditions, operating more partially, produce corresponding effects, under our own eye, among the inmates of prisons, and in the printers, sempstresses, household servants, and others following in-door occupations, and under a great variety of circumstances, in our owm climate.

If, then, similar conditions produce the state of constitution upon which scrofulons affections depend, and that aloo upon which tuberculous affections depend, the etiological distinction falls to the ground.

2. The distinction coming under the second head, appears to me to be as little founded on correct observation as the first. We know well, that, as a general rule, when the system is subjected to any one morbid action, or exhibits any morbid condition in a high degree, this action tends to the prevention of the effects of other agencies; and scrofula is not, as assumed, an exception to this general rule. It is quite true that in the slighter scrofulous affections, where the constitution is but little affected, this cause of exclusion may be inoperative; but in intense scrofulous diseases, characterised by their specific irritative fever, it has as much force as in any other discanes whatever. So again, as respocts tubercle, when the disease of the blood is intense, it does, as a general rule, exclude the operation of other morbific influences, although, as remarked by Dr. Jenner when reviewing my work, in the lighter cases the effocts of the two morbid conditions mas bo met with simultaneoudy.

3. The third head comprises the enunciation of two finctio 
That many instances of intence seroful exist for long periods, without the deposit of tubercle, is, in a certain point of vier, a fact; but it does not establish an eseential pirerence. If the word "scrofula" be taken to mean the local disense, as, for instance, \& scrofulous disease of the hip, then indeed the local disease may be intense and long continued, without a deposit of tubercle, just because the constitutional affection (the morbid state of the blood) is not intense, and is not matured for the production of tubercle. When the constitutional disease is intense, there is, in a corresponding degree, a tendency to the deposit of tubercle, although the existence of the disease, located in a non-rital part, may for a long time prevent the deposit taking place in any vital organ. Of fifty individuals dying of affections denominated "scrofula", forty had tubercles in the internal organs. (On Tuberculosis, p. 366.)

The other fact is, that many instances of tuberculous disease occur without any scrofulous affection. Here again the term "scrofulous" applies to local, and I presume, external scrofulous disesse. When the blood is matured for the deposit of tubercle, and this takes place in one of its seats of election, its occurrence at any other point may for a long time be excluded. Thus the deposit in the external glands may for a long time, and will sometimes permanently, exclude it from the internal organs. When it occurs in the lungs, or other vital organs, the patient is often destroyed before it can be produced elsewhere. The fact ceases to excite any surprise, when we consider that the blood, as well as the organic solids, undergoes proressive changes in health, so that in infancy, youth, adult life, and old age, it differs; and a diseased state of blood mas be modified according to the period of life at which it occurs-a circumstance which goes far to clear up many of the apparent anomalies in the natural history of tuberculous diseases viewed as a whole. The differences in the functional activity of different organs and tissues, at different periods of life, also serve the same end. To make the fact, that consumption so frequently occurs without any external scrofulous affection, a ground of essential difference, is to my mind just as reasonable as it would be to make cancer of the mamma, the pylorus, and the uterus, three different diseases, because either may occur alone, or because it is rare that two or three of them occur coetaneously.

It is singular to remark, with all the ingenuity displayed to preserve the distinction between scrofula and tuberculosis, how that distinction breaks down even in Mr. Paget's hands. In the description of tuberculous diseases of bones, we are informed that they have supplied most of the examples of "scrofulous caries", "Pott's disease of the spine", "podarthrocace", etc.; Mr. Stanley being quoted to show that " completely curable cases of scrofulous disease in bone are those in which the changes have not passed beyond those of simple inflammation", which Mr. Paget defines, "such inflammation as commonly precedes the diffuse deposit of tubercle". In a subsequent page, when comparing tuberculous diseases with certain inflammations, it is stated distinctly that "the same constitutional peculiarities (so far as they can be observed) precede and attend the tuberculous diseases and the so called scrofulous inflammation, which are not productive of tuberculous deposit. Of the lymphatic glands, Mr. Paget remarks, that, whether we disuse or still use, in its vagueness, the term scrofula, "we must be content to be sometimes in doubt whether the substance found in these glands, and commonly known as scrofulous matter, be truly tuberculous matter, or degenerate lymph or pus".

The fact was clearly demonstrated by Dr. Glover and others, that the degenerate pus of scrofulous abscesses, and that of tuberculous carities of the lungs, are identical in physical, microscopical, and chemical characters. Mr. Paget states, that in chronic inflammation in lymphatic glands, in the testis, and in some other parts, or when coute inflammation has subsided, withered or degenerate pus will sometimes sasume the appearance of tuberculous patter, and cannot be dintinguished from it mioroncopically in percons who are not of a corofulous or atrumove contstution, although it is especially frequent in thow who are. But the quection arises, If this peeudo-tuberculous matter and true tuberculous matter present no sensible dif ereaces, how is the nature of anj specimen to be determined? I apprehend, by the history of the case, and by the constitutional symptoms. In constitutions perfoctly free from tuberculosis, degenerate lymph and pus of many varietien often occur; and such degenerations are produced by various constitutional causes, as witnessed in the scorbutic, or in the gangrenous ulcer. Doubtless, also, mere debility will deteriorate the fluids effused in inflammation; but if the degenerate lymph or pus in a lymphatic gland, for instance, bears so close a resemblance to tuberculous matter that it cannot be distinguished from it, there is prima facie evidence of the existence of tuberculosis, and we have no right to assume that it is a product of simple non-scrofulous or non-tuberculous inflammation. We are called upon to examine the antecedents and concomitants, when it will generally turn out, where the characters of the fluid are well marked, that the case is one of tuberculosis, and that the blood of the individual is in that morbid condition upon which both scrofulous ulceration and the tendency to deposit tubercle depends.

Mr. Paget dwells on the vagueness of the term "scrofula", and considers the subject as involved in great "confusion". I believe the confusion arises altogether from making an artificial and arbitrary division into two distinct disesses of that which is essentially one and the same, and classing one set of cases, under the term scrofula, as the subjects of surgical education and practice, and another, under the term consumption or tuberculosis, as the subjects of medical education and practice. Until within a recent period, a surgeon would have been thought mad if he had talked of tubercle in bones. Even in Mr. Paget's work on Surgical Pathology the distinction is, to a certain extent, broken down, as we find by a separate lecture having been deroted to "tubercle", and by some of the best marked scrofulous diseases being transferred to the tuberculous diseases. Viewing the subject according to its natural relations, I cannot admit the existence of any confusion. A difficulty certainly does exist, viz., that of the diagnosis between the less distinctly marked cases of the tuberculous habit and some other morbid states, including debility or delicacy of constitution ; but when we have determined a case to be tuberculous, that is to say, that it exhibits unmistakeably the marks of the tuberculous or "scrofulous" constitution, either with or without any local manifestation of scrofula or tubercle, all the rest is tolerably clear. We know, for instance, that a tuberculous subject is liable to scrofulous inflammation of the brain, or to the deposit of tubercle in the brain or its membranes and hydrocephalus in infancy, to glandular diseases in youth, and to phthisis in adult life. We know that when the local outbreaks consist of some of the milder external affections, these will often expend themselves; the constitutional disease being counteracted either by nature or art; and that such an outbreak with its results may prove a prophylactic against the deposit of tubercle in internal organs. We know, also, that when any of these diseases proceed from bad to worse, and reach a fatal issue uninterruptedly, they terminate in the deposit of tubercle in some vital organ. The whole of these facts, and many others, are rendered intelligible, and the study of their correlations is simplified the moment we admit that tuberculosis and scrofulosis are essentially the same discase, and that the primary seat of that disease is in the blood.

Without entering into the numerous considerations which support the converse doctrine, for the reasons herein stated, I hold that Mr. Paget's attempt to establish an essential difference between the nature and causes of scrofula and of tubercle signally fails. The question is one of the highest practical importance. If the numerous grades and varieties of disease which belong to these designations were more generally regarded as different manifectations of one and the same morbid condition, hydrocephalus, external cerofula, menenterio diseive, purulent affections of joints and cove 


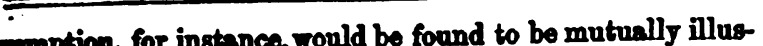
intions of disease being more succesfully studied, practical improvement would moet unquestionably result. I believe it would be advantageous to dispense aitogether with the term scrofula (noine swellings) from our nomenclature, whether scientific or vernacular. The disinclination which patients often have to admit the existence of the diseased condition which they believe it implies, and the prejudice and disgust which it excites, operate very injuriously to the interests of science by inducing them to withhold or garble the truth, and I have for some time past, with great practical advantage, substituted the term tuberculous for scrofulous whenever I have found it necessary to designate the disease.

Norfolk Crescent, Hyde Park, March 1854.

\section{ON THE USE OF CHLOROFORM AS AN AN ÆSTHETIC.}

By H. LOWNDES, Esq., Surgeon to the Liverpool Dispensaries, and late House Apothecary to the Liverpool Royal Infirmary.

[Read before the Liverpool Medical and Pathological Society, November 17th, 1853.]

Doriva my residence at the Infirmary, as well as since that period, it has happened to me to have to admirister chloroform in a very great number of cases. I have paid much attention to its effects; and $I$ have been led, in relation to this subject, to read a little of what has been written on the physiology of respiration.

I will first mention the results at which I have arrived, and which I lay with great deference before this meeting; and will then state, as clearly as I can, the reasons I have to adduce in support of them.

I believe, then, that chloroform may, and often does, prove fatal by its local effect on the peripheral extremities of the branches of the par vagum, and particularly on those of the superior laryngeal nerve; that is to say, by paralysing that nerve, and thus preventing it from conveying any impression to the medulla oblongata. Without venturing to say that this is its only mode, I think that this is its usual mode of destroying life; and that the only way of preventing this effect is to take care that the chloroform is freely diluted with air.

This differs, I believe, from the theories hitherto adduced to explain the action of chloroform, none of which seem to be very satisfactory.

That chloroform and ether do produce a local insensibility of the nerves to which they are applied, has been proved by Dr. Simpson, who, by keeping a man's hand immersed for a sufficient time in the vapour of chloroform, succeeded in producing at least superficial insensibility. In another experiment, two nerves of a rabbit being laid bare, one was immersed in ether, while the other was exposed to the air; in fire minutes, that immersed in the ether was dead to all sensation, while the other retained all its sensibility and power of producing contraction.

I beg now to draw your attention to the physiology of respiration; and the work I shall chiefly refer to is Carpenter's Physiology.

The act of respiration is to some extent under the control of the will. Thus, during sleep, or when the attention is strongly absorbed, the inspirations become fewer, and of a prolonged laborious character; whilst the number of inspirations is always increased by merely trying to count one's own breathing. But, that consciousness is not absolutely a necessary link, for a limited period at least, is shown in sleep and in coms, by anencephalous fotuses, and by decapitated animals.

Respiration is essentially a reflex function; and the upper part of the medulla oblongats is believed to be the narrous centre of this action. The motor or efferent nerves are principally the spinal acceseory and the phrenic and ponterior thoracic, which are both connected with it; and the chief intercostal nerves, which, Dr. Carpenter thinks, probably have their origin in the grey matter of the modulla oblongata. The excitor or afferent is the par vagum. - When this nerve is divided on both sides, the number of inspirations are reduced to one-half. Irritation of its trunk is immediately followed by an act of inspiration. Dr. J. Reid states that, in a kitten a day old, removal of the encephalon reduced the inspirations from a hundred in the minute to forty; and section of the vagus on both sides further reduced them to three or four, and so they continued for some time. As they did not altogether cease then, it would seem to be also influenced by some other power: probably the nerves ramifying on the general surface, and particularly on the face, have this effect; and the fifth nerve appears to be peculiarly concerned in the first inspiration made by the infant. One branch, however, of the par vagum, the inferior laryngeal, appears to be strictly a motor nerve, as it is distributed to the muscles of the larynx, possesses very slight sensibility, and is capable of exciting contraction of the laryngeal muscles when its separated trunk is irritated. The superior laryngeal, on the other hand, appears to be almost solely an afferent nerve, and is principally supplied to the mucous membrane of the larynx. The superior and inferior laryngeal brauches then constitute the circle of incident and motor nerves by which the aperture of the glottis is governed; whilst the superior laryngeal nerve also excites the muscles of expiration, so as to cause the riolent ejection of a blast of air, by which the irritant, of whatever nature, mav be carried off. The mucous membrane of the trachea and bronchi appears also to be endowed with impressibility, so that stimuli applied to it induce expiratory movements; and these evidently operate through the branches of the par ragum distributed upon the membrane.

The incident or afferent nerves, then, chiefly concerned in inducing respiratory movements, are the ramifications of the superior laryngeal on the mucous surface of the larynx, and those of the pulmonary branches of the vagus on the trachea and bronchial tubes.

I wish here to allude to the analogy between the machinery of the act of respiration and that of deglutition. The only important difference is, that the act of deglutition itself is wholly independent of the will, whilst that of respiration, though it can, and often does, proceed independently of the will, is yet, for particular purposes, placed generally under the influence of the will. Deglutition is solely a reflex action; the principal afferent nerve concerned is the glosso-pharyngeal, the principal motor is the pharyngeal branches of the par ragum. This strong analogy leads me to another point. What is the appropriate stimulus to the act of respiration? That is to say, What is it, the influence of which, conveyed to the medulla oblongata, prompts the reflex action of respiration? It has been assigned to two causes. First, it is said, that the sense of venous blood in the lungs requiring oxygen is the exciting cause; and secondly, that the presence of venous blood in the general circulation may he the exciting cause, through the medium of the sympathetic system. But neither want of food in the stomach, nor want of nutritive matter in the general circulation, can cause the reflex act of deglutition; they cause indeed the sense of hunger, but it is the actual presence of $a$ substance in the fauces that is the exciting cause of deglutition; and I believe that it is the presence of air in the larynx and trachea that is the exciting cause of the reflex act of respiration.

It is true that the presence of venous blood in the lungs and in the general circulation will cause a sense of want of air, as the absence of food in the stomach, or the wart of nutritive matter in the circulation, causes the sense of hunger and thirst; and when a person is conscious, he will make voluntary efforts to relieve this want of air. But, whep. a person is in a state of unconsciousness, he cannot make these efforts, any more than he can in that state feed himself. The par vagum, however, still conveys the impression of its proper stimulus, air; and the respiration still goes on, in the ame way that the want of consciousness does not at 